\title{
PERANCANGAN DAN REALISASI SISTEM AKSES PERNIKAHAN DENGAN MENGGUNAKAN KAMERA DAN BARCODE
}

\author{
Stepen Tanggoro ${ }^{1}$, Hadian Satria Utama ${ }^{1}$, Yohanes Calvinus ${ }^{1}$
}

\begin{abstract}
Nowadays, the development of technology is very vast, many conventional systems have turn into an automatic system. Using technology, conventional systems can be turn into an automatic system. In this design, it will change an access system in wedding reception that is changing the guest book filling from manual to automatic using a barcode and a camera. This system also uses a website filled with registry form, attendance form, guest book form and editing form. Moreover, this design has two modules, detection module and register module. The register module function as a guestbook substitute, the detection modul functions as guest detector that pass through and give signal to the register module. Beside register and detection module, a PC (personal computer) is used to update photos to website. In the website, has a data form addition, guestbook form, invitation list form and reservation form. Website functions as a media to process data. Data processing uses a database. Basically every guest will get a card filled with a username and password to access to the website and a barcode as an ID. After some tests, this system manages to delete, add and edit data from the database. Moreover, guests can look into the guestbook, invintation list and make a reservation. With this success this access system can fill a guest book automatically.
\end{abstract}

Keyword : access system, barcode, camera, website.

\begin{abstract}
ABSTRAK: Dewasa ini perkembangan teknologi sangatlah pesat, banyak sistem yang berubah dari sistem konvensional menjadi sistem otomatis. Dengan memanfaatkan teknologi sistem konvensional dapat diubah menjadi sistem yang otomatis. Pada perancangan ini akan merubah sistem akses pada resepsi pernikahan yaitu pengisian pada buku tamu pada resepsi ini akan dibuat menjadi otomatis. Teknologi yang dimanfaatkan pada sistem ini adalah barcode dan kamera. Pada sistem ini memanfaatkan website, website ini berisi form pedaftaran, form kehadiran, form buku tamu dan form edit data. Selain itu, pada perancangan ini digunakan dua modul yaitu modul pendeteksi dan modul registrasi. Modul registrasi berfungsi sebagai pengganti buku tamu dan modul pendeteksi berfungsi untuk mendeteksi tamu yang lewat dan memberikan sinyal ke modul registrasi. Selain modul registrasi dan modul pendeteksi akan digunakan sebuah PC (Personal Computer) yang berfungsi untuk meng-update data foto ke website. Pada website terdapat form tambah data, form buku tamu, form list undangan dan form reservasi. Website ini berfungsi sebagai media pengolahan data, pengolahan data ini memanfaatkan basis data. Pada dasarnya setiap tamu mendapatkan sebuah kartu yang berisi username, password untuk masuk ke website dan ID barcode sebagai tanda pengenal. Setelah melalui pengujian, sistem ini telah berhasil menghapus, menambah dan mengedit data pada basis data. Selain itu, tamu juga dapat melihat buku tamu, list undangan dan dapat melakukan reservasi. Dengan keberhasilan ini maka sistem akses ini dapat mengisi buku tamu secara otomatis
\end{abstract}

KATA KUNCI : Sistem akses, barcode, kamera, website

\section{PENDAHULUAN}

$\mathrm{D}$ ewasa ini perkembangan teknologi sangatlah pesat, hal ini terlihat dari banyaknya sistem yang berubah dari sistem konvensional menjadi sistem yang otomatis. Pada dasarnya sistem konvensional ini masih bergantung terhadap kemampuan manusia sedangkan sistem otomatis ini hanya sedikit membutuhkan kemampuan manusia. Sistem otomatis secara umum dapat didefinisikan sebagai sebuah proses yang urutan operasinya telah ditentukan, dengan tidak menggunakan atau sedikit tenaga kerja [1]. Dengan memanfaatkan teknologi yang begitu berkembang manusia dapat mengubah suatu sistem menjadi lebih teratur dan menjadi sistem yang lebih praktis.

Pada dasarnya dengan memanfaatkan teknologi, sistem konvensional dapat dirubah menjadi bentuk otomatis. Salah satu sistem yang dapat dirubah ke dalam bentuk otomatis adalah sistem akses pada resepsi pernikahan. Pada dasarnya sistem konvensional pada resepsi pernikahan adalah para tamu harus mengisi buku tamu sehingga memerlukan manusia untuk menjaga buku tamu yang cukup banyak. Jumlah pengunjung juga mempengaruhi efisiensi waktu penulisan buku dan jumlah orang yang akan digunakan untuk menjaga meja tamu, jika pada resepsi pernikahan tersebut tamu yang diundang tidak sampai lima ratus orang maka efisiensi saat penulisan buku tamu tidak terlalu diperhitungkan. Apabila tamu yang diundang melebihi lima ratus orang maka efisiensi harus diperhitungkan, hal ini dapat dilihat pada resepsi pernikahan artis yang belakangan ini menjadi pembicaraan banyak orang karena mengundang tamu lebih dari lima ratus orang. Dengan banyaknya tamu yang datang maka akan menyebabkan pemborosan waktu pada saat menulis buku tamu. Faktor keamanan juga merupakan salah satu hal yang penting, jika tamu hanya menulis buku tamu maka semua orang dapat masuk dan keluar dalam resepsi dengan mudah. Tentunya, dengan banyaknya tamu yang masuk secara ilegal ini menyebabkan lemahnya keamanan dan dengan lemahnya sistem keamanan maka akan banyak timbul tindak kejahatan.

Dengan pertimbangan sistem di atas yang memiliki efisiensi waktu dan tingkat keamanan yang rendah, maka dirancanglah suatu sistem otomatis. Sistem otomatis ini memanfaatkan teknologi barcode dan kamera. Barcode pada sistem ini digunakan sebagai tanda pengenal masuk agar hanya orang yang memiliki pengenal dapat masuk. Kamera digunakan untuk mengenal wajah tamu yang diundang. Pada pintu masuk akan dibuat sebuah modul yang terdiri dari kamera, barcode dan pemroses. Modul ini akan tersambung ke server utama dengan menggunakan koneksi internet. Penggunaan koneksi internet ini berfungsi agar dapat dengan mudah mengakses server. Fungsi server pada sistem ini adalah sebagai pengelola data yang masuk dan data yang akan di-update, untuk membantu pengolahan data ini digunakan database. Sistem ini juga dapat mengetahui seberapa banyak tamu yang sudah datang dan melihat tamu yang sudah datang dengan mengakses server. Dengan fitur tambahan ini tentunya akan memudahkan sistem manajemen pernikahan dan pencarian tamu.

\footnotetext{
${ }^{1}$ Prgram Studi Teknik Elektro, Fakultas Teknik Universitas Tarumanagara
} 


\section{KAJIAN PUSTAKA}

Sistem yang dirancang berfungsi untuk mengisi buku tamu secara otomatis. Dalam pengisian buku tamu otomatis ini ternyatan diperlukan modul-modul pendukung yang berfungsi untuk agar dapat mengisi buku tamu

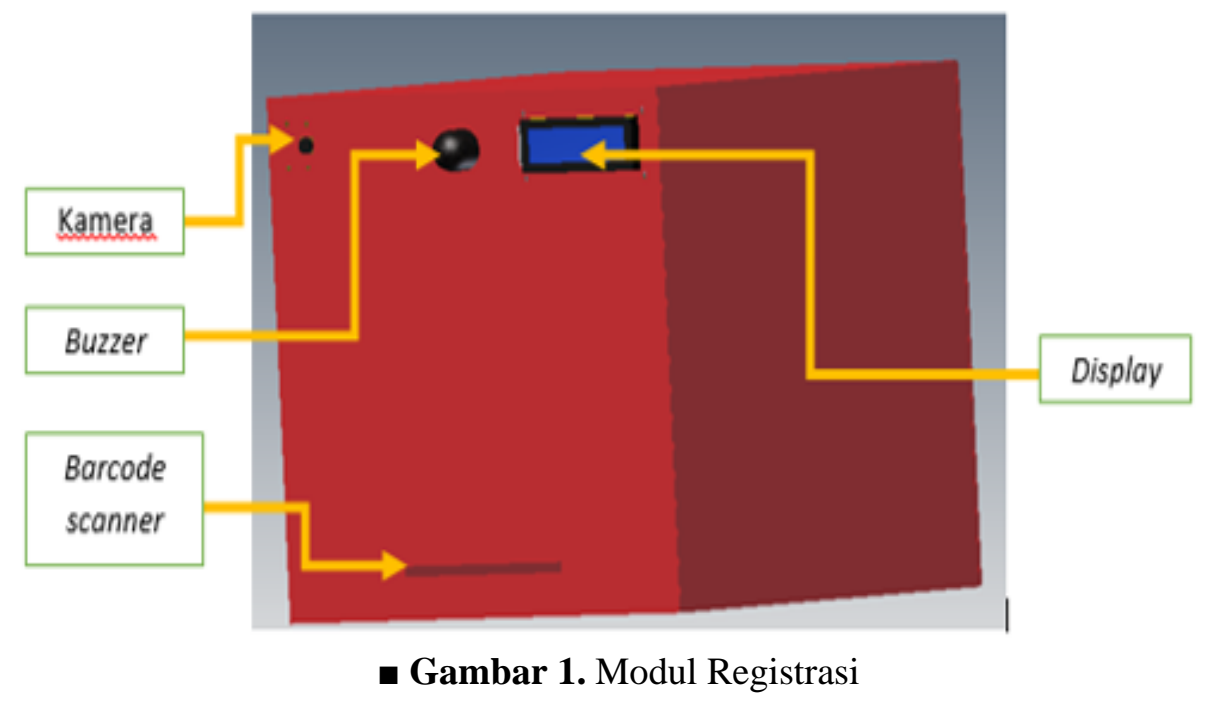

secara otomatis. Untuk menghindari antrian saat pengisian buku tamu digunakan barcode. Untuk pembacaan barcode ini dibutuhkan barcode scanner yang fungsinya mengantikan keyboard, selain itu untuk mengetahui identitas tamu maka diperlukan data-data pribadi seperti alamat, nama lengkap, foto tamu, jenis kelamin.

Pada saat dibagikan undangan, tamu akan mendapat sebuah kartu yang berisikan username, password dan barcode. Ketiga data ini didapatkan dari data-data pribadi tamu yang sebelumnya sudah di-input ke dalam sebuah web dan setiap tamu memiliki ID yang akan dijadikan acuan pada saat pembuatan barcode. Foto tamu akan diambil menggunakan kamera pada saat resepsi berlangsung dan akan di-update ke website. Saat meng-update data ke internet akan digunakan sebuah PC (Personal Computer), tugas PC ini hanya akan memantau data yang masuk dan meng-upload ke internet.

Pada dasarnya untuk memudahkan dalam penyimpanan dan pengolahan data pribadi tamu digunakan basis data. Pada sistem ini, seperti yang sudah dijelaskan di atas maka dibutuhkan beberapa perangkat pendukung seperti PC, barcode scanner, kamera, untuk menggabungkan barcode scanner dan kamera maka digunakan sebuah pemroses. Ketiga perangkat ini akan dijadikan satu modul yang berdiri sendiri dan dinamakan modul registrasi. Pada modul registrasi ini juga dibutuhkan WI-FI, hal ini dikarenakan PC akan membaca data pada modul registrasi sehingga PC dan modul ini harus terhubung pada satu jaringan yang sama. Gambar rancangan pada modul registrasi dapat dilihat pada Gambar 2.

Pada dasarnya modul registrasi ini berfungsi untuk membaca barcode dan mengambil foto pada saat acara berlangsung. Untuk mendeteksi tamu yang lewat pada acara ini maka dibutuhkan suatu sistem yaitu sistem pendeteksi. Pada sistem pendeteksi ini akan dibuat sebuah transmitter dan receiver, pada transmitter akan menggunakan laser dan pada receiver akan menggunakan photodiode. Kedua modul ini disebut modul pendeteksi, ketika tamu lewat maka modul pendeteksi akan mengirim sinyal ke modul registrasi. Modul pendeteksi ini akan diletakkan sebelum modul registrasi. Ketika seorang tamu akan melakukan pengisian buku tamu secara otomatis maka akan melewati modul pendeteksi, selanjutnya modul pendeteksi akan memberi sinyal kepada pemroses untuk memfoto tamu. Selanjutnya, tamu akan menempelkan kartu akses ke dalam modul registrasi yang berisi barcode scanner. Gambar rancangan pada modul pendeteksi dapat dilihat pada Gambar 3

Selain modul registrasi dan pendeteksi, pada sistem ini juga digunakan PC sebagai server yang berfungsi meng-update data dari modul registrasi ke web. Pada web ini akan dibuat form login dan di dalamnya akan berisi form reservasi yang harus dipilih. Reservasi ini akan digunakan agar tamu dapat menentukan kehadiran. Selain form reservasi pada web terdapat fitur untuk melihat tamu yang sudah melakukan reservasi dan yang sudah hadir dalam acara tersebut. 


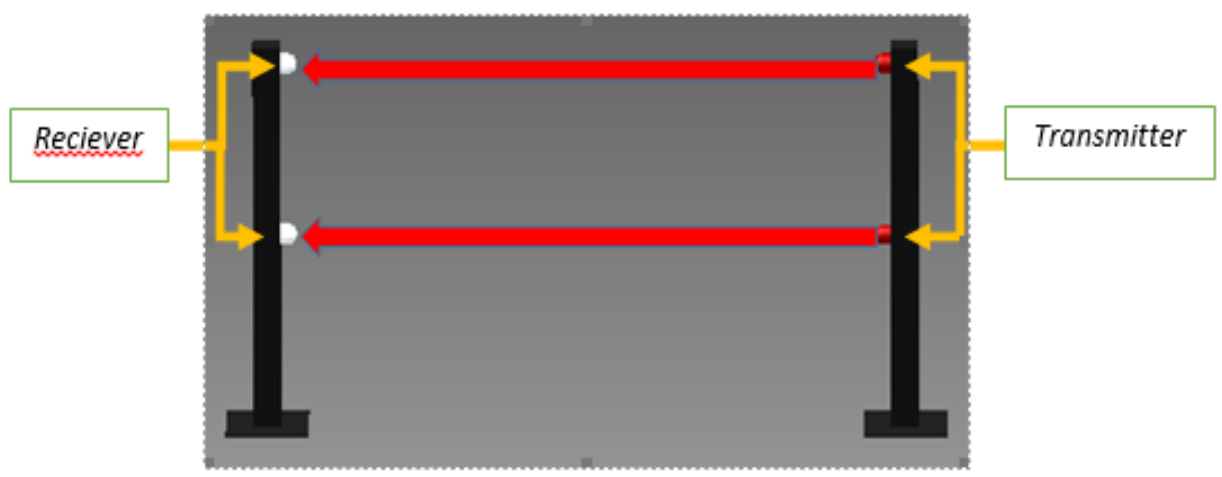

- Gambar 2. Modul Pendeteksi

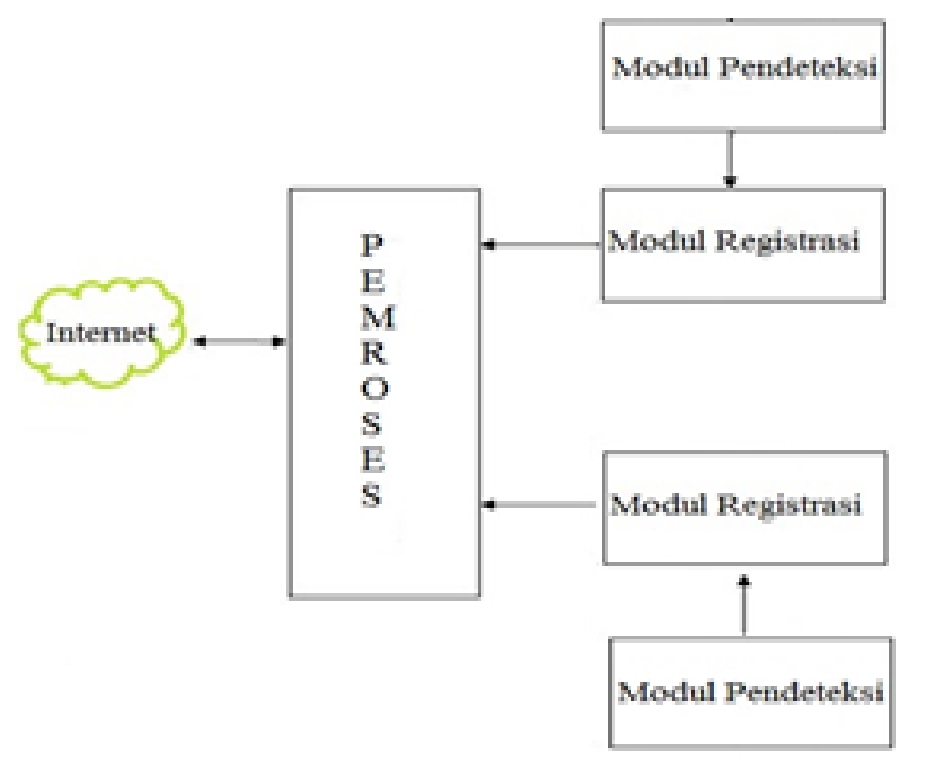

- Gambar 3. Diagram Blok Keseluruhan Sistem

\section{RASPBERRY PI}

Raspberry Pi atau yang biasa disebut Raspi, merupakan sebuah komputer papan tunggal (single board circuit) yang ukuran sebesar kartu kredit. Raspberry Pi dikembangkan oleh Raspberry Pi Foundation yang bertujuan untuk mempromosikan pengajaran ilmu komputer di sekolah dasar. Raspberry Pi memiliki prosesor dengan spesifikasi $700 \mathrm{MHz}$ ARM11. Raspberry memiliki beberapa tipe yang telah diproduksi secara masal yaitu tipe A dan B dan yang terbaru sekarang adalah tipe Raspberry B+ dan Raspberry 2. Raspberry menggunakan SD card sebagai media penyimpanan data dan memiliki beberapa port USB, konektor HDMI, port Ethernet. Sumber yang dibutuhkan untuk menyalakan sebuah Raspberry adalah 5V dengan arus $700 \mathrm{~mA}$. Kelebihan Raspberry memiliki GPIO (General Purpose Input/Output) yang dapat digunakan untuk pembacaan ADC (analog to digital converter), I2C (inter integrated circuit) dan UART (Universal Asynchronous Receiver/Transmitter). Raspberry $\mathrm{Pi}$ ini bersifat open source sehingga pengguna dapat memodifikasi sesuai dengan kebutuhan. Sistem Operasi utama yang biasa digunakan oleh dalam Debian GNU/Linux dan Bahasa pemrograman yang digunakan adalah python dan $\mathrm{C}++$. 


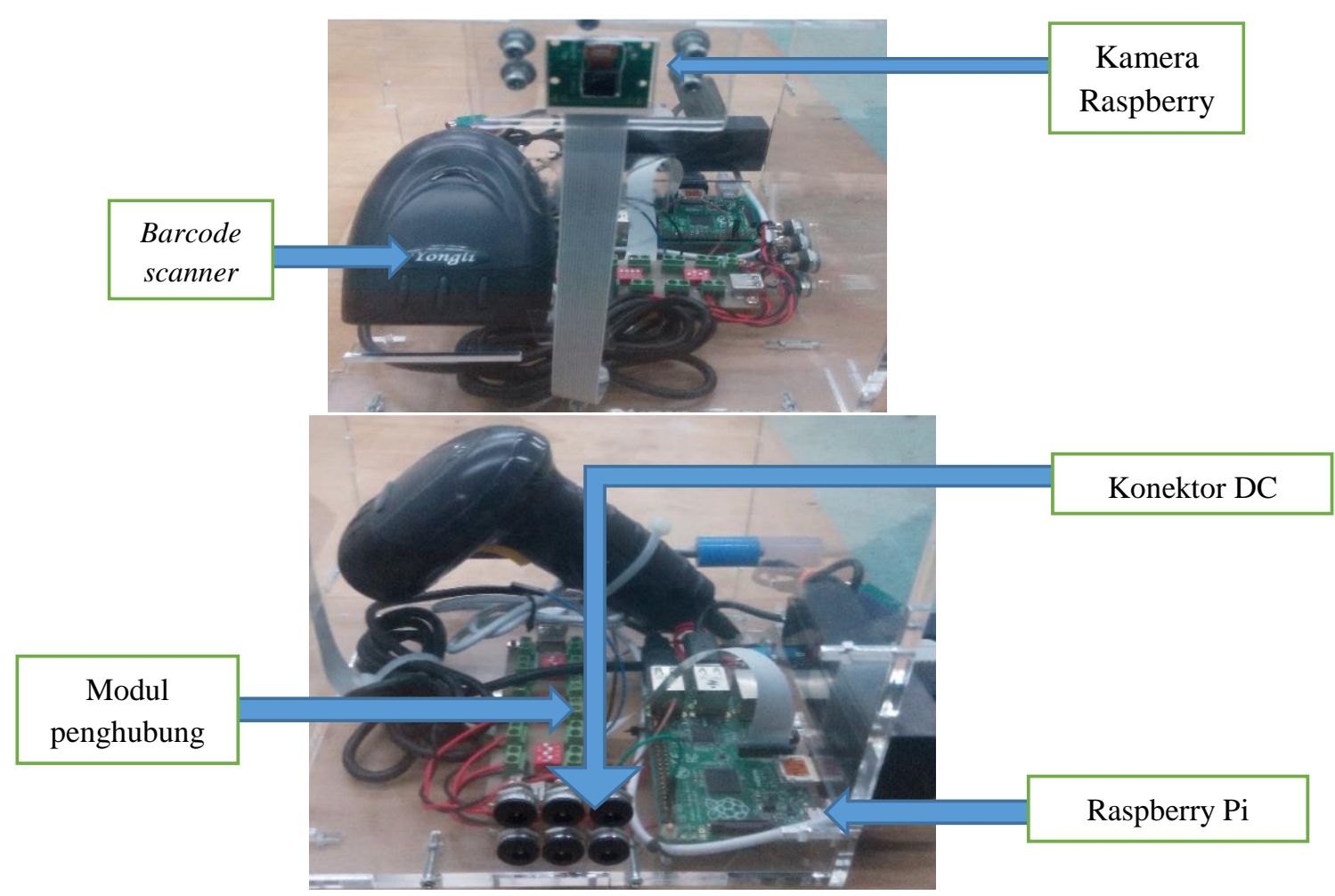

- Gambar 6. Modul Registrasi Tampak Depan dan Samping

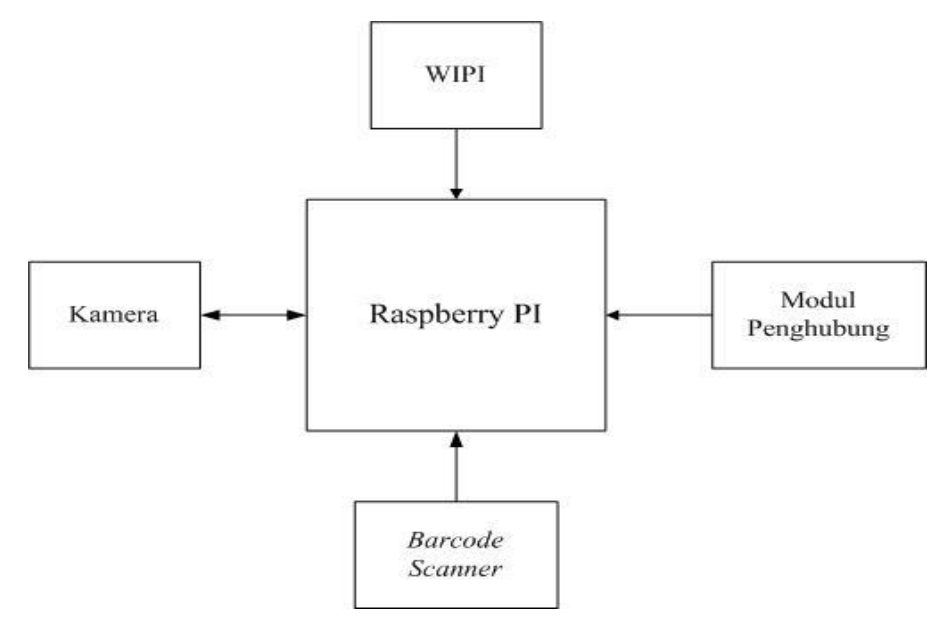

- Gambar 7. Diagram Blok Modul Registrasi

\section{KAMERA}

Kamera adalah alat yang digunakan untuk merekam sebuah objek berupa tempat atau gambar. Prinsip kerja kamera mirip dengan mata, lensa kamera merupakan bagian dari kamera yang berfungsi untuk membentuk bayangan mirip lensa mata pada mata. Berdasarkan mekanisme kerjanya kamera terdiri dari beberapa jenis yaitu kamera single lens reflex dan kamera instan. Berdasarkan jenis media penangkapan cahayanya kamera juga dibagi beberapa jenis yaitu kamera film, kamera digital dan kamera polaroid.

\section{BARCODE SCANNER}

Barcode scanner adalah alat yang digunakan untuk membaca kode-kode berbentuk garis-garis vertikal. Keuntungan dalam penggunaan barcode scanner adalah untuk mengurangi kesalahan operator pada saat memasukan data dan dapat mengurangi antrian karena proses pemasukan data yang cepat. Barcode scanner bekerja seperti sistem digital yaitu warna hitam mewakili nol dan warna putih mewakili satu. Nilai digital ini didapat karena warna hitam akan menyerap cahaya yang dipancarkan oleh barcode scanner dan warna putih akan memantulkan balik cahaya tersebut. Selain itu, ketebalan pada batang barcode memiliki ketebalan yang berbeda sehingga akan diterjemakan ke dalam satu nilai. Ketebalan ini juga menentukan waktu lintasan bagi titik sinar 
pembaca yang dipancarkan oleh barcode scanner. Saat ini terdapat empat jenis barcode scanner yang tersedia di pasaran, tiap jenis juga memiliki perbedaan dalam cara pembacaan atau pengkodean pada barcode.

\section{REALISASI MODUL REGISTRASI}

Pada modul registrasi ini terdiri dari beberapa komponen pendukung yaitu barcode scanner, kamera Raspberry, modul penghubung, Raspberry pi dan WIPI. Bentuk fisik modul registrasi akan ditunjukkan pada Gambar 6. Modul registrasi ini semua kegiatannya dikendalikan oleh Raspberry. Semua perangkat seperti kamera dan barcode scanner akan mengirim data ke Raspberry dan data yang diterima akan ditaruh pada folder tertentu. Folder ini akan di shared sehingga PC dapat membaca folder tersebut. Dalam pembuatan shared folder syarat utama-nya adalah Raspberry dengan PC harus dalam satu jaringan yang sama, karena Raspberry tidak memiliki fitur WI-FI maka pada alat ini ditambah sebuah WIPI. Diagram blok modul registrasi ditunjukkan pada Gambar 7. Pada diagram blok di atas sumber tegangan disuplai oleh catu daya sebesar $5 \mathrm{~V}_{\mathrm{DC}}$ dengan arus 5 Ampere, untuk menghubungkan tegangan ini digunakan konektor DC male dan female.
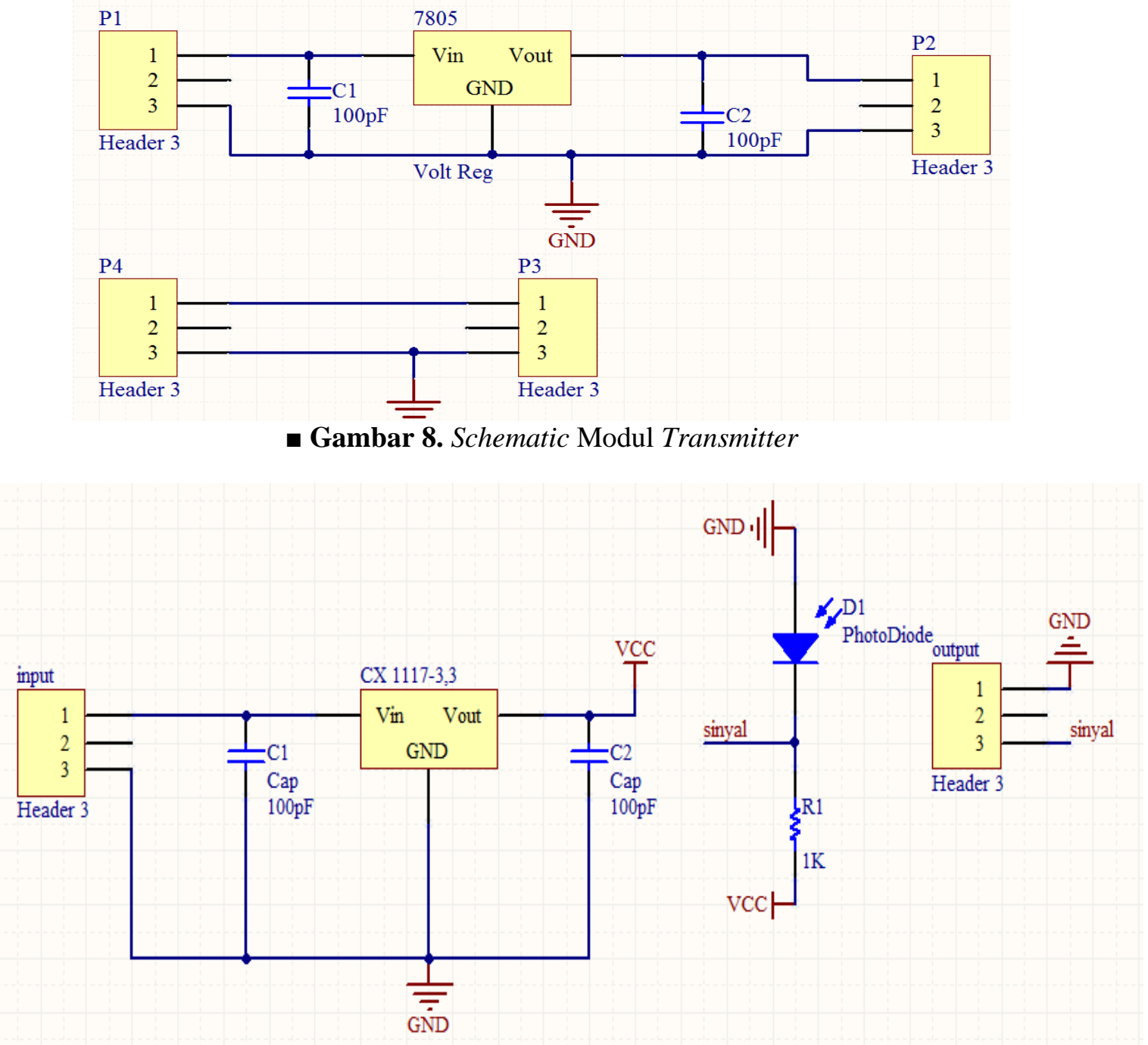

- Gambar 9. Schematic Rangkaian Modul Reciever

\section{REALISASI MODUL PENDETEKSI}

Pada modul pendeteksi ini terdiri dari transmitter dan receiver. Pada transmitter digunakan sebuah laser, laser ini bekerja pada tegangan $5 \mathrm{~V}_{\mathrm{DC}}$. Pada modul transmitter ini digunakan sumber tegangan berupa baterai sebesar $9 \mathrm{~V}_{\mathrm{DC}}$, karena dibutuhkan tegangan $5 \mathrm{~V}_{\mathrm{DC}}$ maka digunakan regulator 7805. Schematic dan bentuk fisik rangkaian transmitter akan ditunjukkan pada Gambar 8. Pada receiver ini digunakan photodiode, photodiode yang digunakan bekerja pada tegangan 3,3 $\mathrm{V}_{\mathrm{DC}}$ hal ini dikarenakan sinyal yang dikeluarkan berupa tegangan akan digunakan Raspberry dan Raspberry dapat menerima maksimal input sebesar 3,3 $\mathrm{V}_{\mathrm{DC}}$. Pada modul ini juga digunkan baterai dengan tegangan $9 \mathrm{~V}_{\mathrm{DC}}$, karena tegangan yang dibutuhkan hanya 3,3 $\mathrm{V}_{\mathrm{DC}}$ maka digunakan regulator CX1117-3,3. Schematic dan bentuk fisik rangkaian reciever akan ditunjukkan pada Gambar 9. Terdapat 
kaki sinyal, kaki ini akan dihubungkan ke modul registrasi menggunakan konektor DC dan kaki sinyal ini akan dipasang pada port GPIO pada Raspberry pi. Sinyal ini yang akan dijadikan acuan pada saat tamu lewat.

\section{REALISASI PERANGKAT LUNAK PADA PC}

Pada perancangan perangkat lunak ini berfungsi untuk meg-upload data dari Raspberry ke website. Untuk memenuhi kebutuhan ini diperlukan beberapa software pendukung, software yang digunakan adalah WinSCP dan Visual Basic 6.0. WinSCP adalah sebuah software yang digunakan untuk meng-upload data meggunakan FTP ke website. Pada sistem ini WinSCP digunakan untuk meng-upload foto tamu dan menaruhnya di website. Software ini pada dasarnya menunggu perintah yang dijalankan secara manual oleh pengguna. Tetapi, karena pada sistem ini diharuskan untuk meng-upload data secara otomatis maka dibutuhkan suatu software yang dapat membantu WinSCP dalam pengirimin dan pembacaan data yang akan di kirim. Software yang digunakan dalam pengotomatisan ini adalah Visual Basic (VB).Visual Basic adalah sebuah Bahasa pemrograman yang dibat oleh Microsoft. Visual Basic menggunakan pendekatan GUI (General User Interface) dalam proses penggunaanya, sehigga proses pembuatan program aplikasi menjadi lebih mudah dan nyaman [5]. Pada perancangan sistem ini digunakan untuk mendeteksi file yang masuk dan meng-uploadnya secara otomatis menggunakan WinSCP. Berikut flowchart program Visual Basic dan lampiran program akan ditunjukkan pada Gambar 10.

\section{Realisasi Perangkat Lunak Pada website}

Pada realisasi perangkat lunak ini digunakan beberapa Bahasa pemrograman yaitu php, css, mysql dan html. Selain itu, digunakan web hosting yang berfungsi sebagai tempat menaruh data-data pada situs. Pada sistem ini data-data yang disimpan adalah data gambar dan basis data. Pada pembuatan website ini ada beberapa form yang dibuat, form ini digunakan untuk mendukung sistem agar berjalan sesuai yang diharapkan yaitu website mampu mengisi data, meng-edit data, melihat data dan reservasi. Pada website ini dibuat hak akses yaitu admin dan guest. Tujuan dibuatnya hak kepemilikan ini adalah agar tamu tidak dapat meng-edit data tamu, jadi hanya admin yang bertanggung jawab terhadap data tamu. Pada admin terdiri dari beberapa form php yaitu menu, cek status login, hapus data, tambah data, edit data dan log out. Pada guest terdiri dari form menu bar, cek status login, buku tamu, list undangan, reservasi, dan log out. Selain kedua form ini terdapat form index dan autentikasi, form index merupakan tampilan awal pada web atau biasa disebut home dan form autentikasi merupakan form yang berfungsi untuk menetukan pengguna sebagai guest atau admin. Pada sistem ini admin diberi ID 00000 sehingga admin dalam hal ini hanya ada satu orang. 


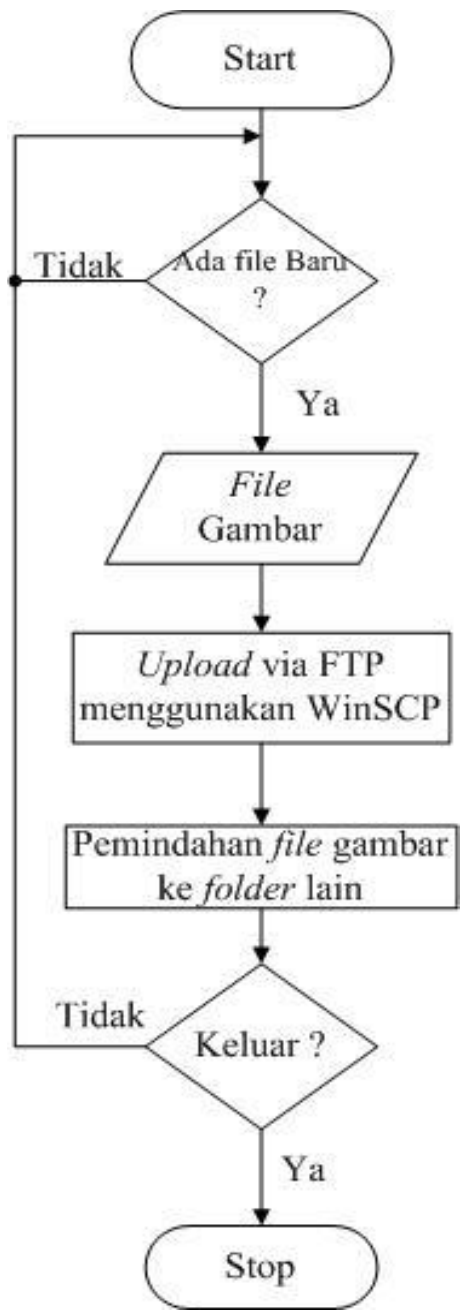

- Gambar 10. Flowchart Program Visual Basic

\section{REALISASI RANCANGAN KESELURUHAN SISTEM}

Dalam merealisasikan sistem secara keseluruhan ini akan digabungkan beberapa modul yaitu modul registrasi, modul pendeteksi, modul perangkat lunak pada PC dan perangkat lunak pada web. Pada dasarnya semua modul yang dibuat merupakan suatu sistem yang saling mendukung dan mempengaruhi, sehingga jika salah satu modul tidak berfungsi dengan baik atau tidak berkerja sesuai dengan fungsinya maka kerja sistem secara keseluruhan akan terganggu. Pada modul registrasi, untuk menghubungkan modul ini dengan modul pendeteksi maka digunakan GPIO sebagai media komunikasi antar modul. Pada modul perangkat lunak pada PC untuk menghubungkan PC dengan modul registrasi maka dibuat shared folder pada direktori home/pi, dan untuk menghubungkan PC dengan web digunakan WINSCP. Pada dasarnya realisasi rancangan secara keseluruhan ini, pertama ketika tamu lewat maka modul pendeteksi akan mengirim sinyal yang terhubung pada GPIO dan modul registrasi akan mengambil foto dan meminta data pada barcode. Setelah itu, maka data yang telah diolah akan ditaruh pada shared folder dan setelah itu PC akan membaca setiap data yang masuk kemudian akan meng-upload data tersebut dan dipindahkan ke folder lain dengan tujuan sebagai history data yang telah dibaca. Ketika data telah di upload ke web maka, data tersebut ditampilkan. Selain itu, fungsi pada perangkat lunak web ini adalah sebagai tempat penyimpanan data tamu secara keseluruhan. 


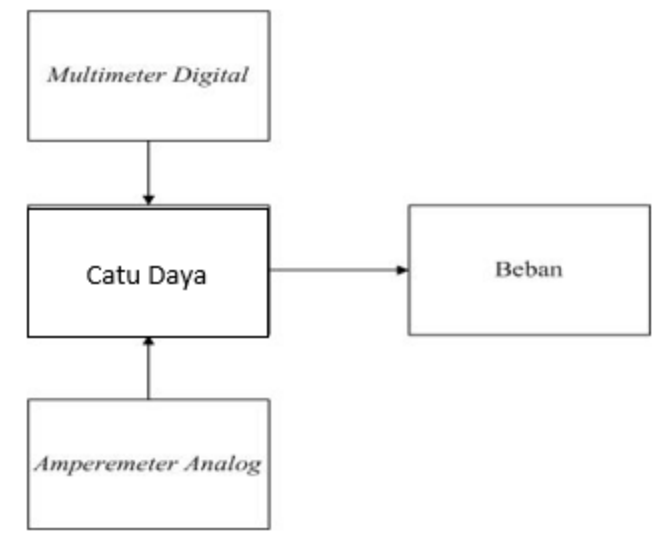

- Gambar 11. Diagram Blok Pengujian Modul Catu daya dengan Beban

- Tabel 1. Tabel Pengujian Catu Daya Tanpa Beban

\begin{tabular}{ccc}
\hline Modul Catu Daya & Tegangan Masukan & Tegangan Keluaran $\left(\mathbf{V}_{\text {DC }}\right)$ \\
\hline LM 7805 & $9,18 \mathrm{~V}_{\mathrm{DC}}$ & $5,03 \mathrm{~V}_{\mathrm{DC}}$ \\
\hline CX1117-3,3 & $9,06 \mathrm{~V}_{\mathrm{DC}}$ & $3,325 \mathrm{~V}_{\mathrm{DC}}$ \\
\hline I.T.E power supply & $220 \mathrm{~V}_{\mathrm{AC}}$ & $5,18 \mathrm{~V}_{\mathrm{DC}}$ \\
\hline
\end{tabular}

\section{PENGUJIAN DAN ANALISIS MODUL}

Pengujian dan analisis bertujuan untuk mengetahui apakah modul yang digunakan bekerja dengan baik atau tidak. Pada pengujian ini ada beberapa modul yang perlu diuji meliputi Modul Catu Daya, Modul Registrasi, Modul perangkat lunak pada Website dan Modul pendeteksi

\section{PENGUJIAN DAN ANALISIS MODUL CATU DAYA}

Pengujian modul catu daya ini bertujuan untuk mengetahui kemampuan catu daya dalam memenuhi kebutuhan setiap modul. Selain kemampuannya memenuhi setiap kebutuhan modul, catu daya ini juga diharapkan memberikan keluaran tegangan yang cukup stabil. Kestabilan tegangan ini sangat berpengaruh terhadap modul yang menerima tegangan. Catu daya pada sistem ini memiliki dua buah sumber tegangan yaitu $9 \mathrm{~V}_{\mathrm{DC}}$ dan $5 \mathrm{~V}_{\mathrm{DC}}$. Sumber tegangan yang digunakan adalah baterai kotak dengan tegangan awal sebesar $9 \mathrm{~V}_{\mathrm{DC}}$ dan satu buah modul catu daya dengan keluaran $5 \mathrm{~V}_{\mathrm{DC}}$ dan arus 5 Ampere. Alat ukur yang akan digunakan dalam pengujian ini adalah multimeter digital dan amperemeter. Berikut diagram blok pengujian tegangan modul catu daya tanpa beban ditunjukkan pada Gambar 11.

Pada pengujian pertama modul catu daya tanpa beban ini menggunakan multimeter, yaitu dengan cara menghubungkan multimeter dengan modul catu daya secara paralel. Hasil pengujian catu daya tanpa beban ditunjukkan pada Tabel 1. Berdasarkan hasil pengujian pada Tabel 1 tegangan yang keluar pada modul catu daya LM7805 adalah 5,03 $\mathrm{V}_{\mathrm{DC}}$, untuk CX1117-3,3 adalah 3,325 $\mathrm{V}_{\mathrm{DC}}$ dan I.T.E power supply adalah 5,18 $\mathrm{V}_{\mathrm{DC}}$. Pada datasheet $\mathrm{LM} 7805$ keluaran tegangan minimal adalah 4,8 $\mathrm{V}_{\mathrm{DC}}$ dan maksimal adalah 5,2 $\mathrm{V}_{\mathrm{DC}}$. Pada pengujian ini keluaran LM7805 masih diantara range tegangan pada datasheet sehingga modul dapat dikatakan bekerja cukup baik. Pada datasheet CX1117-3,3 keluaran tegangan minimal adalah 3,267 $\mathrm{V}_{\mathrm{DC}}$ dan maksimal adalah 3,333 $\mathrm{V}_{\mathrm{DC}}$. Pada pengujian ini keluaran CX1117-3,3 masih diantara range tegangan pada datasheet sehingga modul dapat dikatakan bekerja cukup baik. Untuk I.T.E power supply toleransi yang diperbolehkan adalah sepuluh persen atau pada range $4,5 \mathrm{~V}_{\mathrm{DC}}$ sampai $5,5 \mathrm{~V}_{\mathrm{DC}}$, dengan toleransi ini keluaran dari catu daya masih berada dalam range toleransi dan dapat dikatakan bahwa modul bekerja dengan baik.

Pengujian kedua dilakukan dengan menghubungkan modul catu daya pada beban dan diukur terlebih dahulu tahanannya dengan menggunakan multimeter digital dan Amperemeter. Berikut diagram blok pengujian catu daya dengan beban akan ditunjukkan pada Gambar 11. Pengujian kedua ini akan dilakukan dengan cara memasang mulitimeter secara paralel dan pengukuran arus dilakukan dengan cara memasang Amperemeter secara seri. Berikut tabel hasil pengujian akan ditunjukkan pada Tabel 2. Berdasarkan hasil pengujian dari Tabel 2 terlihat keluaran dari pengujian dengan beban mendekati hasil yang diharapkan yaitu mendekati $5 \mathrm{~V}_{\mathrm{DC}}$ dan $3 \mathrm{~V}_{\mathrm{DC}}$. Pengujian dianggap baik karena menghasilkan keluaran mendekati nilai yang diinginkan.

\section{Pengujian dan Analisis Modul Perangkat Lunak Pada Website}

Pengujian pada modul ini bertujuan untuk mengetahui kemampuan modul apakah modul dapat berkerja sesuai harapan atau tidak. Pada pengujian ini dibagi menjadi dua bagian admin dan bagian tamu. Pada bagian tamu pengujian dilakukan dengan memasukkan data baru, meng-edit data dan menghapus data. Pengujian dilakukan 
dengan memasukkan lima buah data dan data tersebut akan di-edit dan dihapus secara acak. Tabel hasil pengujian akan ditunjukkan pada Tabel 3 .

- Tabel 2. Hasil Pengujian Modul Catu Daya dengan Beban

\begin{tabular}{ccccc}
\hline Modul Catu Daya & $\begin{array}{c}\text { Tegangan } \\
\text { Masukan } \\
\left(\mathbf{V}_{\mathbf{D C}}\right)\end{array}$ & $\begin{array}{c}\text { Beban } \\
\text { Sistem } \\
(\mathbf{\Omega})\end{array}$ & $\begin{array}{c}\text { Tegangan Keluaran } \\
\left(\mathbf{V}_{\mathbf{D C}}\right)\end{array}$ & $\begin{array}{c}\text { Arus Keluaran } \\
(\mathbf{m A})\end{array}$ \\
\hline LM 7805 & 8,14 & $3,248 \mathrm{~K}$ & 5,02 & 39,33 \\
\hline CX1117-3,3 & 9,04 & 355,6 & 3,306 & 21,45 \\
\hline I.T.E power supply & 5,18 & $6,7 \mathrm{M}$ & 5,03 & 680 \\
\hline
\end{tabular}

Tabel 3. Pengujian Pada Bagian Admin

\begin{tabular}{cccc}
\hline Pengujian ke- & Insert data & Edit data & Hapus data \\
\hline 1 & Berhasil & Berhasil & Berhasil \\
\hline 2 & Berhasil & Berhasil & Berhasil \\
\hline 3 & Berhasil & Berhasil & Berhasil \\
\hline 4 & Berhasil & Berhasil & Berhasil \\
\hline 5 & Berhasil & Berhasil & Berhasil \\
\hline
\end{tabular}

Tabel 4. Hasil Pengujian Pada Bagian Tamu

\begin{tabular}{cccc}
\hline ID Tamu & Buku tamu & List Undangan & Reservasi \\
\hline ID 1 & Berhasil & Berhasil & Berhasil \\
\hline ID 2 & Berhasil & Berhasil & Berhasil \\
\hline ID 3 & Berhasil & Berhasil & Berhasil \\
\hline ID 4 & Berhasil & Berhasil & Berhasil \\
\hline ID 5 & Berhasil & Berhasil & Berhasil \\
\hline
\end{tabular}

Berdasarkan hasil pengujian pada Tabel 3 dapat disimpulkan bahwa modul perangkat lunak website, pada bagian tamu berfungsi dengan baik karena pada saat pengujian dapat mengisi, edit dan hapus data dengan baik. Pengujian kedua pada bagian tamu dilakukan dengan login dengan menggunakan lima ID tamu. Setelah itu, akan dilihat hasil dari keluaran buku tamu, list undangan dan reservasi. Tabel hasil percobaan dapat dilihat pada Tabel 3. Berdasarkan hasil pengujian pada Tabel 4, dapat disimpulkan bahwa pada bagian tamu semua perangkat lunak dapat berkerja sesuai yang diharapkan.

\section{PENGUJIAN DAN ANALISIS MODUL PERANGKAT LUNAK PADA PC}

Pada pengujian modul perangkat lunak pada PC, bertujuan untuk mengetahui kemampuan perangkat lunak dalam mendukung kerja jadi sistem. Pada pengujian kali ini perangkat lunak yang digunakan adalah program monitoring pada VB, WinSCP dan dataware barcode. Pengujian pertama dilakukan dengan cara memasukkan lima buah data dan menjalakan perangkat lunak pada VB. Berikut tampilan ketika data terbaca dan akan ditunjukkan pada Gambar 12. Ketika kelima data masuk hasilnya adalah ke-lima data terbaca dan siap untuk diUpload oleh WinSCP. Pada pengujian ini dapat disimpulkan perangkat lunak pada VB bekerja dengan baik karena dapat membaca seluruh data yang dimasukkan. Pengujian ke-dua dilakukan dengan cara menggabungkan VB dengan WinSCP. Berikut tampilan pada WinSCP akan ditunjukkan pada Gambar 13 menunjukkan pada saat Upload data pada WinSCP. Pengujian dilakukan dengan memasukkan lima buah gambar pada VB dan VB akan memanggil WinSCP untuk melakukan upload data. Tabel hasil pengujian akan ditunjukkan pada Tabel 7.

WinSCP berhasil melakukan upload data. Pada pengujian WinSCP ini dapat disimpulkan bahwa WinSCP berjalan dengan baik. Pengujian ketiga bertujuan untuk menguji barcode generator pada software dataware barcode. Berikut tampilan dataware barcode akan ditunjukkan pada Gambar 14. 


\section{9:32:11 AM: Application Started}

9:32:11 AM: Start Monitoring New Incoming Files in E:|Auto_FTP_Upload toto\}

9:32:12 AM: New File (20150619171952.jpg) Detected. Preparing to upload

- Gambar 12. Tampilan Pada VB

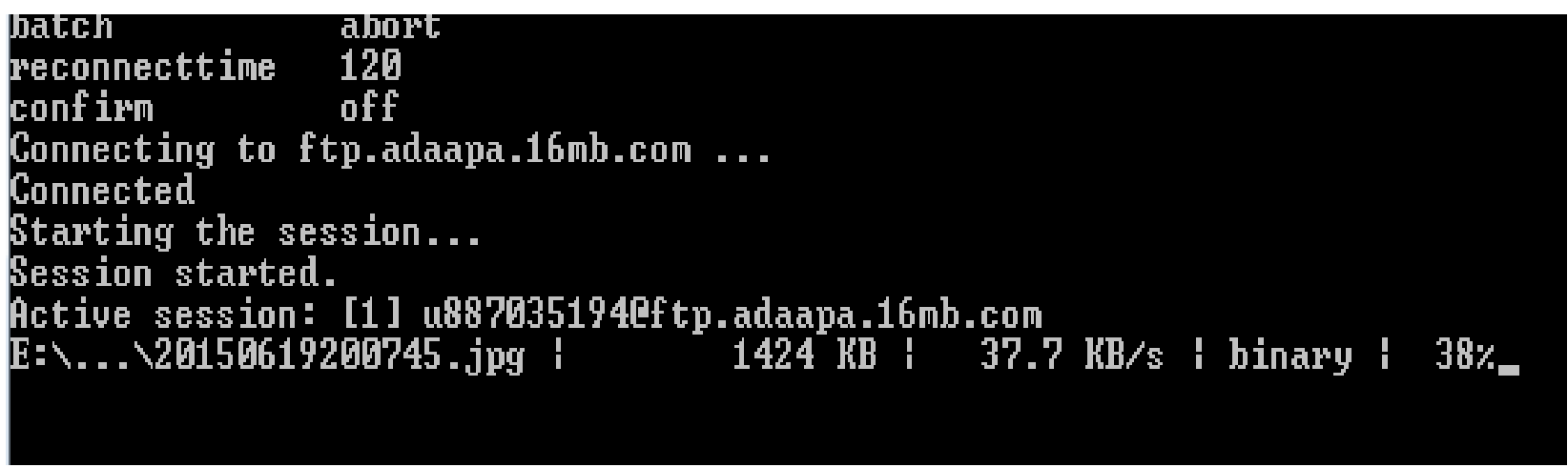

- Gambar 13. Tampilan pada WinSCP

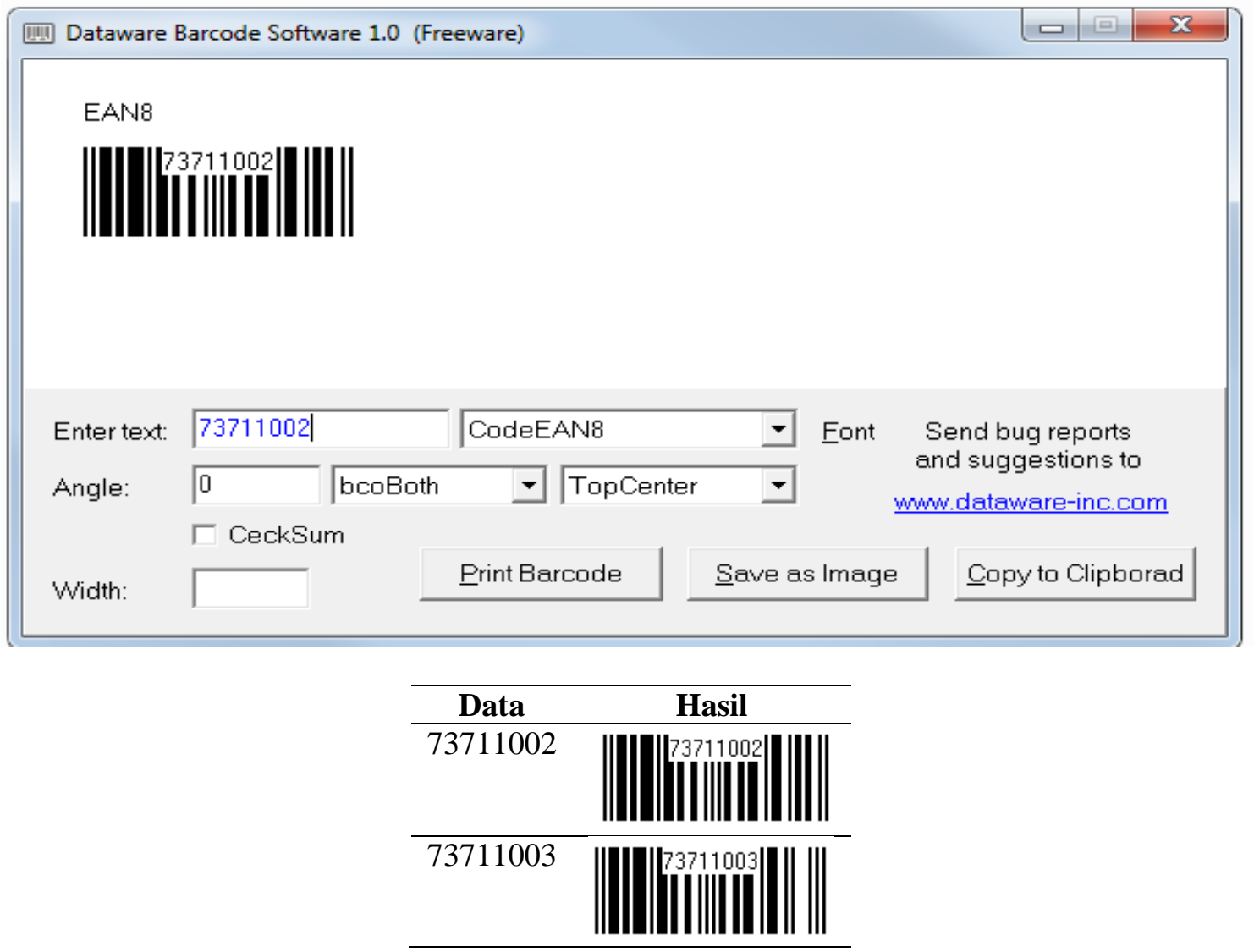

- Gambar 14. Tampilan dan hasil dataware barcode

Berdasarkan Gambar 14, kode yang digunakan dalam pengujian ini adalah EAN8.

\section{PENGUJIAN DAN ANALISIS KESELURUHAN SISTEM}

Pengujian keseluruhan sistem ini bertujuan untuk mengetahui kemampuan sistem yang dibuat dapat bekerja dengan baik atau tidak. Pengujian keseluruhan sistem dilakukan dengan cara melakukan simulasi. Pada simulasi ini mengambil lima sample dari lima orang tamu. Lima orang tamu ini akan diberikan kartu yang berisi barcode, username dan Password yang sebelumnya telah didaftarkan di website. Sebelum acara dimulai, tamu juga dapat melakukan reservasi di website dan data tamu yang sudah atau belum melakukan reservasi akan ditampilkan di website. 
Pada pengujian ini tamu pertama akan melewati modul pendeteksi, dan modul pendeteksi akan memberikan sinyal kepada modul registrasi untuk mengambil gambar. Setelah gambar diambil, tamu akan menempelkan kartu ke modul registrasi. Kartu yang ditempelkan ini memiliki ID, ID ini akan digunakan untuk menamai gambar yang sebelumnya telah diambil. Kemudian setelah melakukan penamaan, maka secara otomatis PC akan membaca gambar yang masuk pada folder tertentu. Gambar yang di baca ini akan di-upload ke website. Setelah gambar di-upload maka gambar akan dipindahkan ke backup folder. Pada website akan muncul gambar tamu yang telah melakukan registrasi. Berikut tabel pengujian akan ditunjukkan pada Tabel 5.

\section{KESIMPULAN}

Modul registrasi dapat melakukan pengambilan foto secara otomatis dan pengisian nama foto sesuai dengan data barcode. Pada PC dapat melakukan pembacaan data dan meng-upload secara otomatis. Website berhasil melakukan pengisian, penghapusan dan peng-editan data. Selain itu, website juga berhasil memperlihatkan buku tamu, reservasi dan list undangan.

Tabel 5. Pengujian Keseluruhan Sistem

\begin{tabular}{ccccccc}
\hline Tamu ke- & $\begin{array}{c}\text { Pengambilan } \\
\text { gambar }\end{array}$ & $\begin{array}{c}\text { Registrasi } \\
\text { barcode }\end{array}$ & Reservasi & $\begin{array}{c}\text { Upload } \\
\text { data }\end{array}$ & $\begin{array}{c}\text { Pembukaan } \\
\text { buku tamu }\end{array}$ & $\begin{array}{c}\text { Melihat list } \\
\text { undangan }\end{array}$ \\
\hline 1 & Berhasil & Berhasil & Berhasil & Berhasil & Berhasil & Berhasil \\
\hline 2 & Berhasil & Berhasil & Berhasil & Berhasil & Berhasil & Berhasil \\
\hline 3 & Berhasil & Berhasil & Berhasil & Berhasil & Berhasil & Berhasil \\
\hline 4 & Berhasil & Berhasil & Berhasil & Berhasil & Berhasil & Berhasil \\
\hline 5 & Berhasil & Berhasil & Berhasil & Berhasil & Berhasil & Berhasil \\
\hline
\end{tabular}

\section{DAFTAR PUSTAKA}

[1]. A.K. Gupta and S.K. Arora, Industrial Automation and Robotics. 2nd ed. New Delhi: University Science Press, 2011, hal. 1.

[2]. R. Boylestad and L. Nashelsky, Electronic Devices and Circuit Theory. New jersey: Prentice Hall International Inc, 1992, Ch:19 pp. 773-797

[3]. H. Rahmat, Mooduto, dan Yuhefizar, Cara Mudah Membangun Website Interaktif Menggunakan Content Management System Joomla (CMS). Jakarta : PT Elex Media Komputindo, 2009, hal. 2.

[4]. F.K. Alexander, Kitab Suci Web Programing.Yogyakarta : MediaKom, 2011, hal. 10.

[5]. R. Arief, Seri Penuntun Praktis Microsoft Visual Basic 6.0. Jakarta: PT Elex Media Komputindo, 2004, hal.2. 